\title{
An Assessment of Health Expenditure Determinants in Nigeria
}

\author{
Folahan, D. Awe and Awe, A.A. \\ Department of Economics, Ekiti State University Ado-Ekiti, Nigeria
}

\begin{abstract}
The study examined the determinants of health expenditure in Nigeria. The stidy covers a period of 34 years that is between 1976 and 2010. Cointergartion and error correction model was used to estimate a model that expressed health expenditure as a function of number of physicians, number of nurses, number of hospitals, reported cases of Malaria, HIV AIDS, tuberculosis, population and the GDP. The result showed that number of physicians, number of nurses, and number of hospitals have a long run positive relationship with health expenditure in Nigeria. Their effects are also significant showing that they are important determinants of health expenditure in Nigeria. However, cases of various diseases such as Malaria, HIV AIDS, and tuberculosis did not have a significant long run relationship with health expenditure. This shows that the bulk of health expenditure in Nigeria goes to payment of salaries while little is left for health facilities maintenance and development. Again expenditure on the diseases in Nigeria appears not to commensurate with the cases of diseases. It is recommended that government should improve in the area of capital expenditure so as to improve health care provision in Nigeria.
\end{abstract}

Key Words: Health expenditure, determinants, long run relationship

1.1 Background to the study

I. Introduction

Good health is a crucial part of well being. The health status of the people in any nation is a critical index of a nation's social and economic development. Improved health contributes to economic growth in several ways: it increases production, permits the use of natural resources that had been totally or nearly inaccessible because of disease, increases enrollment of children in school and puts them in better condition to learn, resources that would otherwise have been spent on treating illness. There are other evidences confirming the importance of good health in economic development. Health is one of the most important assets that human have as it permits us to fully develop our capabilities. Therefore, there is a growing concern to extend the relationship between heath and economic growth, since health is a capital productive asset and an engine of economic growth, Aguayo-Rico, (2005).

Nigeria operates three-tier health care system. The first is the primary health care level. This is usually the first point of contact between the patient and the health delivery system. The institutional component at this level includes public health clinics and centers, dispensaries, private clinics and maternity centers. Following this is the secondary system which components are mainly hospitals of all kinds - general, cottage and mission hospitals. The tertiary system includes the teaching hospitals as well as specialist hospitals. With the foregoing arrangements of health care delivery system, Nigeria still falls among the developing nation with low health service delivery. The factors responsible for this may include - greater disparity in the distribution of health institutions and personnel between town and country, poverty, low level of literacy, poor nutritional standards, Oloruntuyi (2003).

It is worthwhile to mention that Nigerian government at all levels is making concerted efforts to solve the problem of acute health services delivery. More medical and nursing schools are built and existing ones expanded to train more doctors and nurses. Infrastructures are put in place, particularly in rural areas.

\subsection{Statement of the problem}

For a nation to have a sound economic growth, the health status of the human capital must be taken seriously. This underscores the importance of health expenditure in the budget of any country. World Health Organization (WHO) cited meager budget allocation to the health sector in many developing countries as the major problem confronting their health sector (WHO, 1984). In Nigeria, there are myriads of problem confronting the health sector, this range from lack of medical personnel to non-provision of infrastructural facilities. All these problems account for several health problems like high infant mortality rate, low rate of life expectancy and prevalence of many deadly diseases like AIDS, tuberculosis among others.

Various researches have been conducted around issue relating to health expenditure in Nigeria and in other countries. For instance, Anyanwu (2008) examined health expenditure and health outcomes in Nigeria, Ogundipe (2011) assessed health expenditure and Nigeria economic growth, Bakare (2011) also examined health care expenditure and economic growth in Nigeria, Bloom (2004) investigated the determinants of health 
seeking behaviour in Uganda, and Filmer (2003) studied the determinants of provincial health expenditure in Canada among others. It could been seen that none of these researchers examined determinants of health expenditure, they are more concerned about the relationship between health expenditure and economic growth. The only research that is, Filmer (2003) that studies determinants of health expenditure focused on the Canadian economy which is a developed economy and not Nigeria.

On this note, this research work hopes to empirically appraise health expenditure in Nigeria with a view to identifying its major determinants as well as critically assessing the relationship between each determinant and health expenditure in Nigeria. This will pave way for a more comprehensive appraisal of health sector expenditure in Nigeria and consequently lead to emergence of a more vibrant health sector made possible through improved funding.

\section{Literature}

Bloom and Canning (2001) studied the effect of health on economic growth, using a production function model of economic growth to account for two additional variables that micro economists have identified as fundamental components of human capital: work experience and health. The main results, is that health has a positive and statistically significant effect on economic growth. The study suggests that a one year improvement in a population life expectancy contributes to an increase of 4 percent in output.

Anyanwu and Erhijakpor (2007) assessed health expenditure and health outcomes in Nigeria. The study provided econometric evidence linking African countries' per capita total as well as government health expenditures and per capita income to two health outcomes: infant mortality and under-five mortality. This relationship is examined, using data from 47 African countries between 1999 and 2004. They found out that health expenditures have a statistically significant effect on infant mortality and under-five mortality. The magnitude of the elasticity estimates are in consonance to those reported in the literature. For African countries, their results imply that total health expenditures (as well as the public component) are certainly important contributor to health outcomes. In addition, they also found out that both infant and under-five mortality positively and significantly affect the health outcomes, higher numbers of physicians and female literacy significantly reduce these health outcomes. According to them, these results have important implications for attaining the targets envisioned by the Millennium Development Goals (MDG).

Abu and Abdulahi, (2010) examined government expenditure and economic growth in Nigeria and observed that rising government expenditure has not been translated to meaningful development as Nigeria still ranks among world's poorest countries. In an attempt to investigate the effect of government expenditure on economic growth, they employed a disaggregated analysis. The results revealed that government total capital expenditure (TCAP), total recurrent expenditures (TREC), and government expenditure on education (EDU) have negative effect on economic growth. On the contrary, rising government expenditure on transport and communication (TRACO), and health (HEA) results to an increase in economic growth. Their recommendations included among others the following; firstly, government should increase both capital expenditure and recurrent expenditure, including expenditures on education, as well as ensuring that funds meant for the development of these sectors are properly managed, secondly, government should increase its investment in the development for business to strive, thirdly, government should raise its expenditure in the development of the health sector since it would enhance labour productivity and economic growth, lastly, government should encourage and increase the funding of anti-corruption agencies in order to tackle the high level of corruption found in public offices.

Bakare and Olubokun (2011) investigated the relationship between health care expenditures and economic growth in Nigeria. The ordinary least square multiple regression analytical method was used to examine the relationship between health care expenditures and economic growth. The data analysis showed a significant and positive relationship between health care expenditures and economic growth. The study thus recommended that Nigeria policy makers should pay closer attention to the health sector by increasing its yearly budgetary allocation to the sector. Nevertheless, the key to good results lies not in ordinarily increasing particular budgetary allocation but rather, in implementing a public finance system that to the extent possible, links specific expenditure and revenue decisions and ensure the usage of the allocated fund as transparently as possible.

In conclusion, after considering different opinions of various authors discussed above about what variables should be considered determinants of health expenditure, we therefore identify the following determinants are numbers of nurses and midwives, numbers of physicians, total population, capital expenditure such as building and maintenance of hospitals and health centers and finally social expenditure.

\section{Model specification}

Following the Kee (2001) model of slope homogeneity the government health expenditure is expressed as a function of health status, federal transfer to provinces, the share of publicly funded health expenditure, the share of senior population and income. But Roberts (1999) expatiated share of publicly funded health 
expenditure to include expenses on Physicians and other health workers. Again, according to the Commission for Macroeconomics and Health (2001) communicable diseases like HIV-AIDS, Tuberculosis and Malaria are very crucial in determining health care expenditure especially in the sub Sahara African Countries. Consequently, a modified form of Kee's model of determinants of health expenditure is expressed thus:

$$
H E=\alpha_{0}+\alpha_{1} P H Y+\alpha_{2} N N M+\alpha_{3} N H P+\alpha_{4} M A L+\alpha_{5} T B C+\alpha_{6} H I V+\alpha_{7} P O P+\alpha_{8} G D P \text {. }
$$

where

Health expenditure (HE)

Total number of physicians (PHY)

Total number of nurses and midwives (NNM)

Total Number of hospital (NHP)

Malaria (MAL)

Tuberculosis (TBC)

Human Immuno-deficiency/Acquired Immune Deficiency Syndrome (HIV)

Total population (POP)

Gross domestic product at current factor cost (GDP)

\section{Estimation technique}

The estimation procedures employed in this empirical investigation is based on Johansen and Joselius co-integration analysis and error correction model (ECM). The choice of this estimation procedure is informed by the need to determine the time series characteristics of the variables that are used in this study. The Johansen co-integration is the statistical equivalence of the economic theoretic notion of stable long-run equilibrium. The existence of the concept among the variables of the model provides somewhat conclusive evidence on the existence of stable equilibrium relationships among them. The process of co-integration is discussed as follows:

\section{Unit Root Test}

Currently, there are some commonly accepted methods of testing for unit roots. These are the DickeyFuller (DF), Augmented Dickey-Fuller (ADF) test and the Philip Peron (PP) test.

The Augmented Dickey-Fuller (ADF) test is considered superior to the Dickey-Fuller (DF) test because it adjusts appropriately for the occurrence of serial correlation.

$$
X_{t}=b_{0}+b_{1} X_{t-1}+b_{2} X_{t-2}+b_{n} X_{t-n}+U
$$

Where $\mathrm{U}$ is a stationary error term. The null hypothesis that $\mathrm{X}_{\mathrm{t}}$ is non stationary is rejected if $\mathrm{b}_{1}$ is significantly negative.

The number of lag (n) of $X_{t}$ is usually chosen to ensure that the regression is approximately white noise. It is simply referred to as the DF test if no such lags are required in which case $b_{i}=0(i=1 \ldots \ldots \ldots \ldots n)$. However, the t-ratio from the regression does not have a limiting normal distribution.

Thus, a time series $X_{t}$ is stationary if its mean $E(X t)$ is independent of time and its variance $E\left\{X_{t}-E\right.$ $\left(\mathrm{X}_{\mathrm{t}}\right)^{2}$ \} is bounded by some finite number and does not vary systematically with time. It tends to return to its mean with the fluctuations around this mean having constant amplitude.

\section{(B) Co-integration and Error Correction Model}

The theory of multivariate co-integration, as propounded and propagated by Johansen and Joselius provides a nexus or connection among integrated processes and the notion of long run equilibrium.

The co integration test commenced with a test for the number of co-integrating relation or rank (r) of $\pi$ using Johansen's maximal Eigen value of the stochastic matrix and the likelihood Ratio (LR) test based on the trace of the stochastic matrix $\pi$ which is the long - run multiplier matrix of $\mathrm{mx} \mathrm{n}$ that is the matrix of the coefficients. Note that the Eigen value of $\pi 1$ are the roots of the kth order characteristic polynomial $\left|\Pi_{1}-\mathrm{vI}\right|$ obtained by solving the characteristic equation

$$
\left|\Pi_{1}-\mathrm{v} I\right|=0
$$

The number of non - zero Eigen value is the rank of the matrix $\pi$. Also, the trace statistic suggested by Johansen to determine the co- integration rank in a multivariate model is based on the ordered (estimated) Eigen value in the following relation.

$$
\operatorname{Trace}\left(r_{0} / k\right)=-T \sum_{i r=r_{0}+1}^{K} \ln \left(1-\lambda_{i}\right) \text {. }
$$

Where $\quad \lambda i=$ ordered (estimated) Eigen value.

This is the relevant test statistic for the null hypothesis $r \leq r_{o}$ against the alternative $r \geq r_{0}+1$ following a sequence (This sequence has been fully discussed under chapter three) 
$\Pi$ matrix (the matrix of the coefficient in the VAR models) is a product of two matrices $\alpha$ and $\beta$. Let $Y$ denote an $\mathrm{n} \times 1$ vector of the I (1) variables the rank of $\pi$ which is $r$, determines how many linear combination of the variables in the levels are stationary. If $r=o$ such that $\pi=0$, none of the linear combination are stationary. $\Pi$ can be factored, that is $\pi=\alpha \beta$. Both $\alpha$ and $\beta$ are $\mathrm{nx} \mathrm{r}$ matrices. While $\beta$ contains the co-integrating vector (the error - correction mechanism in the system), $\alpha$ is the adjustment parameter.

The second is the maximum Eigen value $\left(\lambda_{\max }\right)$ statistic:

$$
\lambda_{\text {max }}=-T \ln \left(1-\lambda_{r+1}\right)
$$

This test allows for the comparison of a cointegrating rank of $r$ against the alternative of a cointegrating rank of $r+1$. This test may then be repeated for larger values of $r$ until one fails to reject the null hypothesis.

The Johansen representation theorem establishes formally the theoretical basis of error-correction modeling. According to the theorem, if $\mathrm{y}_{\mathrm{t}}$ and $\mathrm{X}_{\mathrm{t}}$ are co-integrated, then there is a long run relationship between them. In addition, the theorem proves that the short-run adjustment dynamics can be usefully described by the error correction model (ECM) as stated in the following equation:

$\left.\mathrm{a}(\mathrm{L}) \Delta \mathrm{Y}_{\mathrm{t}}=\mathrm{a}_{\mathrm{o}}-\chi\left(\mathrm{Y}_{\mathrm{t}}-\mathrm{d}_{\mathrm{i}} \mathrm{X}_{\mathrm{t}}\right)+\mathrm{b}(\mathrm{L})\right) \Delta \mathrm{Y}_{\mathrm{t}}+\mathrm{C}(\mathrm{L}) \Sigma_{\mathrm{t}}$

In simple terms, the ECM involves using the lagged residual to correct for deviations of actual values from the long run equilibrium values. To fix ideas, consider the equation above and will discover that the residual from that regression is $\mathrm{U}_{\mathrm{t}}=\mathrm{y}_{\mathrm{t}}$. $\mathrm{BX} \mathrm{X}_{\mathrm{t}}$ which is $1(0)$, since $\mathrm{y}_{\mathrm{t}}$ and $\mathrm{X}_{\mathrm{t}}$ are assumed to be con-integrated. In applied work we require that the coefficient of ECM be significant and negative. Its sign should be negative if it is to play the role of error correction. Specifically, if actual equilibrium value is too high, the error correction term will reduce it, while if it is too low, the error correction term will raise it.

\section{Result And Discussion}

Before exploring the time series properties of the variables, descriptive statistics was first used to examine the behavior of the variables and the trend over the years, these include the summary of statistics ranging from measures fo variation and dispersion

Table 1 Descriptive Statistics

\begin{tabular}{|l|l|l|l|l|l|}
\hline Variable & observation & Mean & $\begin{array}{l}\text { Standard } \\
\text { Deviation }\end{array}$ & Min & Max \\
\hline LHE & 30 & 18.51202 & 3.644719 & 14.21607 & 23.09574 \\
\hline LNPHY & 30 & 10.14535 & .4759593 & 9.274817 & 10.95084 \\
\hline LNNM & 30 & 11.71844 & .3785877 & 10.87625 & 12.3921 \\
\hline LNHP & 30 & 10.06387 & .6262081 & 9.212338 & 10.81316 \\
\hline LHIV & 30 & 14.62811 & .4260799 & 13.28788 & 15.00943 \\
\hline LTUB & 30 & 6.04611 & .2633001 & 5.590987 & 6.356108 \\
\hline LMAL & 30 & 14.47819 & .5145204 & 13.72082 & 15.27312 \\
\hline LPOP & 30 & 18.50108 & .2150891 & 18.14022 & 18.85563 \\
\hline LGDP & 30 & 25.54347 & .5562785 & 24.75466 & 26.56339 \\
\hline
\end{tabular}

Source: Computed by the Author

The descriptive statistics shows that the mean of health expenditure is high but with a low variance. The implication is that the health expenditure might not have shown significant variations over the years. Similar dimension was exhibited by the LNPHY and LNNM but LNHP shows a higher level of variance thus; indicating that there has been a relatively high variation in the numbers of hospital established over the years. For the diseases, that is LHIV, LTUB and LMAL all of them showed very low variance over the period under study but the mean appears to be a bit high.

Table 2 Covariance Matrix

\begin{tabular}{|c|l|l|l|l|l|l|l|l|l|}
\hline & LHE & LNPHY & LNNM & LNHP & LPOP & LGDP & LHIV & LTUB & LMAL \\
\hline LHE & 1.0000 & & & & & & & & \\
\hline LNPHY & 0.8485 & 1.0000 & & & & & & & \\
\hline LNNM & 0.5189 & 0.7879 & 1.0000 & & & & & & \\
\hline LNHP & 0.9598 & 0.8369 & 0.4633 & 1.0000 & & & & & \\
\hline LPOP & 0.8852 & 0.9885 & 0.7475 & 0.8848 & 1.0000 & & & & \\
\hline LGDP & 0.8165 & 0.9863 & 0.8399 & 0.8000 & 0.9842 & 1.0000 & & & \\
\hline LHIV & 0.8878 & 0.7832 & 0.4882 & 0.9116 & 0.8217 & 0.7514 & 1.0000 & & \\
\hline LTUB & 0.8959 & 0.8792 & 0.4363 & 0.9211 & 0.9113 & 0.8345 & 0.8309 & 1.0000 & \\
\hline LMAL & 0.8048 & 0.9147 & 0.6245 & 0.8317 & 0.9361 & 0.9060 & 0.7182 & 0.9143 & 1.0000 \\
\hline
\end{tabular}

Source: Computed by the Author

The covariance matrix shows various correlations among the variables of interest. It is very apparent from the result on the table that virtually all the variables show very high correlation with the health expenditure. The 
implication of this is that all the variable are most likely going to be important determinant of health expenditure in Nigeria.

\section{Time series properties of variables in the model.}

The ADF test for unit root was conducted for the variables in the model at both levels and first difference. Accordingly the null hypothesis is that there is a unit root in each variable, that is each variable is non-stationary the rule of thumb is that the null hypothesis of unit root should be accepted if both ADF and PP statistics are less negative than the critical value, otherwise, the direction of the alternative hypothesis.

Table 3: ADF Unit Root Tests For Selected Series

\begin{tabular}{|c|l|l|}
\hline \multirow{2}{*}{ Series } & ADF Unit Root Test \\
\cline { 2 - 3 } & \multicolumn{1}{|c|}{ Test Statistics } & Order of Integration \\
\hline LHE & $\mathbf{- 5 . 2 9 8} * * *$ & $\mathbf{I}(\mathbf{1})$ \\
\hline LNPHY & $\mathbf{- 6 . 5 6 8} * * *$ & $\mathbf{I}(\mathbf{1})$ \\
\hline LNNM & $\mathbf{- 4 . 1 7 8} * *$ & $\mathbf{I}(\mathbf{1})$ \\
\hline LNHP & $\mathbf{- 4 . 7 6 8} * * *$ & $\mathbf{I}(\mathbf{1})$ \\
\hline LHIV & $\mathbf{- 2 1 . 0 7 0} * *$ & $\mathbf{I}(\mathbf{0})$ \\
\hline LTUB & $\mathbf{- 3 . 4 5 3} *$ & $\mathbf{I}(\mathbf{1})$ \\
\hline LMAL & $\mathbf{- 3 . 4 3 4} * *$ & $\mathbf{I}(\mathbf{1})$ \\
\hline LPOP & $\mathbf{- 4 . 2 1 8} * *$ & $\mathbf{I}(\mathbf{1})$ \\
\hline LGDP & $\mathbf{- 4 . 5 4 3} * * *$ & $\mathbf{I}(\mathbf{1})$ \\
\hline \multicolumn{2}{|l|}{} \\
\hline \multicolumn{2}{|l|}{ significance at $10 \%, 5 \%$, and $1 \%$ respectively }
\end{tabular}

Source: Computed from data

After performing the trend analysis of each series using the line graph, the test in table 3 was conducted with the assumption of constant trend in the series. This is so because each of the variables show a relationship with line, that is trended. The result in Table 3, therefore indicate that all variables are non-stationery at their levels except HIV. This is so as the their ADF statistics are all less negative than the critical values at both the $1 \%$ and $5 \%$ level of significance. The economic implication of non-stationary series is that of a prolonged or sustained shock if there is any disturbance to the variable. Thus health expenditure (HE), number of physician (NPHY), number of nurses and midwives (NNM), number of hospitals (NHP) hiv disease (HIV), tuberculosis (TUB) malaria (MAL), population (POP) and gross domestic product (GDP) all exhibit persistent shock.

A further test for unit root to ascertain whether such shock is that of infinity or will die out over time is conducted using the first difference and second difference of each variable as the case may be. The result, also in table 3, shows that all the variables are stationary at their first difference and therefore integrated of order one denoted as I(1) except HIV that is stationary at levels I(0). Since all series are non-stationary and are mostly integrated of order one i.e I(1), a necessary condition for conducting cointegration test is met. The result of the Johansen maximum likelihood cointegration test and the associated error correction model are presented as follows:

\section{Cointegration rank test on health expenditure and its determinants}

The test is conducted using the Johanssen cointegration technique since the model is multivariate. The result of the multivariate cointegration is presented in table 4

Table 4: Johansen Multivariate Cointegration Rank Test

\begin{tabular}{|l|l|l|l|l|l|l|l|}
\hline Trace & & & & $\Lambda \max$ & & & \\
\hline Ho & $\mathrm{H} 1$ & Stat & $95 \%$ & $\mathrm{Ho}$ & $\mathrm{H} 1$ & Stat & $95 \%$ \\
\hline $\mathrm{r}=0$ & $\mathrm{r}=1$ & $627.3671 *$ & $197.3709^{*}$ & $\mathrm{r}=0$ & $\mathrm{r}=1$ & $188.6535^{*}$ & 58.43354 \\
\hline $\mathrm{r} \leq 1$ & $\mathrm{r}=2$ & 438.7136 & 159.5297 & $\mathrm{r} \leq 1$ & $\mathrm{r}=2$ & $154.0404 *$ & 52.36261 \\
\hline $\mathrm{r} \leq 2$ & $\mathrm{r}=3$ & 284.6731 & 125.6154 & $\mathrm{r} \leq 2$ & $\mathrm{r}=3$ & 87.90330 & 46.23142 \\
\hline $\mathrm{r} \leq 3$ & $\mathrm{r}=4$ & 196.7698 & 95.75366 & $\mathrm{r} \leq 3$ & $\mathrm{r}=4$ & 68.68445 & 40.07757 \\
\hline $\mathrm{r} \leq 4$ & $\mathrm{r}=5$ & 128.0854 & 69.81889 & $\mathrm{r} \leq 4$ & $\mathrm{r}=5$ & 47.66565 & 33.87687 \\
\hline $\mathrm{r} \leq 5$ & $\mathrm{r}=6$ & 80.41975 & 47.85613 & $\mathrm{r} \leq 5$ & $\mathrm{r}=6$ & 39.63850 & 27.58434 \\
\hline $\mathrm{r} \leq 6$ & $\mathrm{r}=7$ & 40.78124 & 29.79707 & $\mathrm{r} \leq 6$ & $\mathrm{r}=7$ & 26.01357 & 21.13162 \\
\hline $\mathrm{r} \leq 7$ & $\mathrm{r}=8$ & 14.76767 & 15.49471 & $\mathrm{r} \leq 7$ & $\mathrm{r}=8$ & 14.08523 & 14.26460 \\
\hline
\end{tabular}

NOTE: The * indicates statistical significance at the $5 \%$ level

$$
\begin{aligned}
& H E=35.23+0.4445307 L N P H Y+2.277 L N N M+5.4916 L N H P-0.3161 L H I V \\
& \begin{array}{lllll}
(506.29) & \text { (5.17188) (4.3767) } & \text { (2.763402) } & \text { (1.3900) }
\end{array} \\
& \text {-1.6479LMAL+ 4.1759LTUB -2.5378LPOP+1.0235LGDP ....(4.1) } \\
& \begin{array}{lllll}
(1.5748) & \text { (5.34184.) (58.57499) (0.010665) }
\end{array}
\end{aligned}
$$

The Long run test of Johansen is based on both trace statistics and maximal Eigen value; look for the number of ranks in multivariate vector. The null hypothesis of no cointegration is rejected at $r=0, r \leq 1$ to $r \leq$ 6 , since at this levels, both the trace test and maximal Eigen values are greater than their respective critical 
values at 5\% level of significance. Thus the test indicates 6 cointegrating equations. The evidence of cointegration indicates that all the identified determinants will influence health expenditure. The cointegrating equation normalized to health expenditure is shown in equation 4.1.

From the equation, it is clear that in the long-run, number of physician (NPHY), number of nurses and midwives (NNM), number of hospitals (NHP), tuberculosis (TUB) and gross domestic product (GDP) impact positively on health expenditure during the period under review. While hiv disease (HIV), malaria (MAL), and population (POP) are contrary to expectations by having inverse relationship with health expenditure.

It should be noted that our variables of interest namely NPHY, NNM and NHP showed a direct relationship with the health expenditure this might not be unconnencted with the fact the salaries of health workers are primarily given priority whenever there will be any change in health budget of the country. According to UNICEF (1993) the largest chunk of Nigeria's health expenditure is allocated for payment of salaries of health workers. Again NHP showed a positive relationship too which simply means that the higher the number of hospital the higher the health expenditures and vice versal, this is also in accordance with the apriori expectation, but UNICEF (1993) again maintained that many of the hospitals in Nigeria were not given enough allocation in the health budget to take care of their maintenance and repairs.

Out of the three diseases that their prevalence are usually used as health indicators by the WHO that is TUB, HIV and MAL. The result shows that two namely HIV and MAL exhibited a negative relationship with health expenditure. This means that increase in the prevalent rate of these diseases did not, necessarily lead to increase budget allocation to reduce the prevalent rate of these deadly diseases. This is in line with the WHO (2004) report that categorized Nigeria as a country seriously ravaged by the incidence of these deadly diseases. Again, POP this used as a control variable according to our result also demonstrated an inverse relationship. This is an indication that as the population of Nigeria rises every year government has reneged on its responsibilities to increase expenditure on health.

Considering the individual statistical significance of the parameter estimates, our result showed that, parameter estimates of both NPHY and POP are statistically significant at $10 \%$ level while parameter estimates of GDP and NHP are statistically significant at 5\% level. The rest of the variables are not statistically significant. This is an indication that the four variables have significant impact on health expenditure in Nigeria more than others. The outcome underscores the importance of both salaries of physicians and expenditure on building of hospitals in determining health expenses in Nigeria. A further test to confirm the overall significance of the model was conducted and the result was shown through the F test. The result showed that the model is statistically significant since the $\mathrm{F}$ value of 115.45 is significant at $5 \%$ level. This is an indication that all the variables identified as the determinants of health expenses as used in the model jointly have significant impact on health expenditure in Nigeria during the period under review.

To corroborate these findings, our result showed that the value of the R square is 0.977 . This implies that about $97 \%$ variation in health expenditure is explained by the determinants identified. This strongly supports the selection of the variables used in the model. The Durbin Watson value of 1.62 is an indication that the model is not affected by the problem of autocorrelation.

In conclusion, all the variables used as determinants in our model have the expected significant impact on the health expenditure in Nigeria during the period under review

Moreover, the following inferences are drawn from the cointegration rank test.

(i) The trace test and the maximal Eigen value support the evidence of at least six significant co integrating vectors, which implies the existence of a long-run and stable relationship between health expenditure and the identified determinants;

(ii) The normalized first cointegrating regression on $\mathrm{HE}$ indicates the presence of positive but relatively significant link with numbers of health workers(NPHY and NNM) and number of hospitals (NHP) in Nigerian health sector;

(iii) Health expenditure shows a negative but not significant relationship with major disease prevalence such as HIV, TUB and MAL.

These findings however are consistent with the findings and opinions of UNICEF and WHO as initially explained in the previous discussions. However, all the variables are not stationary at all levels but at first and second difference as the case may be therefore, we estimate the short-run dynamics that is the error-correction mechanism (ECM). The results are given in Tables 4.5 and 4.6.

\subsection{Error correction mechanism}

The evidence of cointegration indicates that health expenditure will be influenced by all the identified determinants in the long run. When cointegration exists, the Engel-Granger theorem establishes the encompassing power of ECM over other forms of dynamic specification. The ECM is specified in the parsimonious form. 
TABLE 6 ECM Parsimonious Model

\begin{tabular}{|l|r|r|r|r|}
\hline Variable & Coefficient & Std Error & t-stat & Prob \\
\hline$\Delta$ HE(-1) & 0.131474 & 0.709084 & 0.185413 & 0.8552 \\
\hline$\Delta$ NPHY(-1) & 124476.1 & 99783.10 & 1.247467 & 0.2302 \\
\hline$\Delta$ NPHY(-2) & 167472.1 & 77771.74 & 2.153380 & 0.0469 \\
\hline$\Delta$ NNM(-1) & 4747.188 & 13520.03 & 0.351123 & 0.7301 \\
\hline$\Delta$ NHP(-1) & 83500.91 & 76981.95 & 1.084682 & 0.2941 \\
\hline$\Delta$ POP(-1) & -127.1018 & 96.56764 & -1.316195 & 0.2067 \\
\hline$\Delta$ GDP(-2) & 0.008610 & 0.038343 & 0.224558 & 0.8252 \\
\hline$\Delta$ HIV(-1) & -1422.009 & 1205.891 & -1.179219 & 0.2555 \\
\hline$\Delta$ TUB(-1) & 5644427. & 4116841. & 1.371058 & 0.1893 \\
\hline$\Delta$ MAL(-2) & 462.9733 & 453.3012 & 1.021337 & 0.3223 \\
\hline ECM(-1) & -0.631234 & 0.841225 & 0.750374 & 0.0639 \\
\hline C & $4.30 \mathrm{E}+09$ & $4.65 E+09$ & 0.924058 & 0.3692 \\
\hline
\end{tabular}

$\mathbf{R}^{2}=\mathbf{0 . 9 7} ;$ F. stat $=70.77 ;$ Prob. of F. stat. $=0.0000$

The overall impact of the identified determinants on health expenditure in the short-run is very high the $\mathrm{R}$ square is (0.97) in the parsimonious model, it will also be recalled that it was the same value of $\mathrm{R}$ square in the long run equation, this is an indication that the strong impact of these determinants on health expenditure in Nigeria is sustained from the short run through the long run.

From the result, ECM (-1) coefficient is used to determine the speed and direction of adjustant to equilibrium when there is disequilibrium. The negative sign in the ECM indicates that the adjustant is in the right direction to restore the long-run relationship. The ECM coefficient in Table 6 is 0.63124 , meaning that approximately 63.1 percent feedback from the previous value of health expenditure. The economic implication of this result is straight forward. It implies that there was a disequilibrium in previous health expenditure since ECM coefficient is non-zero in which case, some changes in these determinants are necessary to restore equilibrium since the coefficient of ECM is less than zero.

\section{Conclusion}

The empirical result in this research work has led to some revelations regarding the relationship between the health expenditure and its determinants in Nigeria. Firstly, we can conclude from the findings in this empirical study that their existed a long-run relationship between health expenditure in Nigeria and its major determinants during the period under review. Again, it can be deduced from the results that number of physician (NPHY), number of nurses and midwives (NNM), number of hospitals (NHP) and gross domestic product (GDP) all have a direct relationship with health expenditure in Nigeria. This is an indication that if these variables increase health expenditure will also rise. This corroborates the assertion of UNICEF (1993) that the largest chunk of our health budget in Nigeria are used for payment of salaries of health workers and leave virtually nothing for maintenance and repair of health facilities.

Another important revelation from our result is that two major diseases out of three, that is HIV and MAL together with POP showed an inverse relationship with the health expenditure in Nigeria. On one hand, this simply means that even when the prevalent rates of these diseases are rising, the health expenditure in Nigeria may not rise. Again, it also showed that a rise in population of the country does not necessarily mean rise in expenditure. The implication of this is that a very small amount of our health budget if any at all is allocated to reduce the prevalent rate of these deadly diseases. In addition, number of physician (NPHY), number of hospitals (NHP), gross domestic product (GDP) and population (POP) all individually have significant impact on health expenditure in Nigeria. This showed that they have more influence on health expenditure in Nigeria than others.

Finally, the model passed the overall statistical test of significance. And the result showed that about $97 \%$ variation in health expenditure in Nigeria is explained by all the variables used consequently, we can conclude that the variables appeared to be major and important determinants of health expenditure in Nigeria during the period under review and it is important for policy makers to pay more attention to them.

\section{References}

[1]. Abu N., Abdulahi U. (2010) "Government Expenditure and Economic Growth in Nigeria, 1970-2008: Journal of management science, Vol 2 No. 16

[2]. Aguayo-Rico A, Iris A. (2005): Empirical Evidence of the Impact of Health on Economic Growth. American Journal of Economics, Vol 2 No. 28.

[3]. Alves, D and Belluzzo, W (2005), "Child Health and Infant Mortality in Brazil", Inter-America Development Bank Research Network Working Paper R- 493.

[4]. Arnand, S. and Ravallion M. (1993), "Human Development in Poor Countries: On the Role of Public Services" Journal of Economics Perspectives 7(1), $135-50$. 
[5]. Anderson, R. (1975), "Health services distribution and equity," in Equity in health services: Empirical analysis in social policy; R. Andersen et al. (eds.), Ballinger, Cambridge MA, Chapter 2.

[6]. Anwaynwu, J. C., and Erhijakpor A. E. (2007) "Health Expenditures and Health Outcomes in Africa" Economic Research Working Paper 91 (December)

[7]. 23, 177-200.

[8]. Bakare, A. S., Olubokun S. (2011) "Health Care Expenditure and Economic Growth in Nigeria: An Empirical Study. Journal of Economics and Social Sciences Vol 2, No 4.

[9]. Baker, L.C. and Wheeler S. K. (2000). Managed care and technology diffusion the Case of mri. Health Affairs 17, $195-207$.

[10]. Baldacci, E., Guin-Sui M. T. and Mellow L. (2002), "More on the Effectiveness of Public Spending on Health Care and Education: A Covariance Structure Model," International Monetary Fund Working Paper WP/02/09, Washington, DC.

[11]. Baltagi, B. H. (2001) "Econometric Analysis of Panel Data," Second Edition, Wiley and Sons.

[12]. Barro, R and Sala-I-Marton X., (1995) Economic Growth. New York: McGraw-Hill.

[13]. Baumol, W. J. (1993), Health Care, Education and Cost Disease: A Looming Crisis for Public Choice. Public Choice, $77(1), 17$ - 28.

[14]. Bloom, D and Canning, D., (2003), "The Health and Poverty of Nations: From Theory to Practice." Journal of Human Development, 4(1) $47-71$.

[15]. Bloom, D and Canning, D., and Jaypee S., (2004), "The Effect of Health on Economic Growth: A Production Function Approach." World Development, 32(1) $1-13$.

[16]. Cremieux, P.Y., Meilleur M.C., Outllette P., Petit P., Zelder M., and Potvin K. (2005a), "Public and Private Pharmaceutical Spending as Determinants of Health Outcomes in Canada." Health Economics 14(2), 107-116.

[17]. Cutler, D. M. (1995), "The incidence of adverse medical outcomes under prospective payment" econometrical 63 (1), 29-50.

[18]. Di Matteo, L. (2004). What drives provincial health expenditure? Canadian Tax Journal/Revenue scale canadienne Canadian Tax Journal 52, 1102.

[19]. Dormont B., Gringnon M. and Huber H., 2006. Health expenditure growth: reassessing the threat of ageing. Health Economics, 15(9), pp.947-963.

[20]. Dregen C. and Reimers H. E. (2005), Health Care Expenditure in OECD Countries: A Panel Unit Root and Cointegration Analysis. International Journal of Applied Econometrics and Quantitative Studies. 2, 5 - 20. IZA Discussion Paper n.1469.

[21]. Federal Ministry of Health (1988) National Health Policy and Strategy to Achieve Health for All Nigerians, Lagos; FMOH.

[22]. Filmer A., (2003), Impact of Health Expenditure on the Growth of Canadian Economy. Journal of Health Economic Vol. 1 No. 4.

[23]. Fisher G. W. (1964): Determinants of State and Local Expenditures; A Preliminary Analysis in National Tax Journal, Vol. XIV, No 4, Dec. 349-355.

[24]. Gerdtham, U. G. and Johnson B. (1998), The Determinants of Health Expenditure in the OECD Countries: A Pooled Data Analysis. In P. Zweifel, ed. Health, The Medical Profession and Regulation. Boston: Kluwer Academic Publishers, 113-134.

[25]. Gotter P. and Schieber G. (2006), "Health Financing Revisited: A Practitioner's Guide, “The World Bank, Washington, D. C.

[26]. Granger, C. W. J., (1969) Investigating Casual Relations by Econometric Models and Cross-Spectral Methods. In Econometrica. JSTOR, 424-438.

[27]. Gupta, S., Verhoeven, M., and Tiongson, E. R. (2003), Public Spending on Health Care and the Poor. Health Economics, 12(8), 685696.

[28]. Hartwig, J. (2008), What Drives Health Care Expenditure? Baumol's Model of Unbalanced Growth Revisited. Journal of Health Economics 27, 603-623.

[29]. Harttgen, K and Misselhom, M (2006), A Multilevel Approach to Explain Child Mortality and Undernutrition in South Asia and SubSaharan Africa Ibero America Institute for Econ. Research (IAI) Discussion Papers, September.

[30]. Issa, H. and Ouattara, B. (2005), "The Effect of Private and Public Health on Infant Mortality Rates: Does the Level of Development Matters?" May 2005.

[31]. Johansen and Joselius (1989), Cointegration Analysis. McGraw Hill Press, New York.

[32]. Kee, G. S. (2001), "An Empirical Analysis of Canadian Public Health Care Spending and Health. 1975 to 1996" Master's Thesis, Calgany University of Calgary.

[33]. Kessler, D., and McClellan M. (2000), “Is Hospital Competition Socially Wasteful?” Quarterly Journal of Economics, 115, 577-615.

[34]. Keynes, J. M. (1935), Money Treatise. Cambridge University Press.

[35]. Nwaobi, G. C. (2006) 'Modeling the Health Sectors in Nigeria: Quantitative Economic Research, Anambra State, Nigeria.

[36]. Ogundipe, M. A., and Lawal, N. A (2011) Health Expenditure and Nigerian Economic Growth.

[37]. Okunade, A. A. and Karakus, M. C., (2001), Unit Root and Cointegration Tests: Time Series Versus Panel Estimates for International Health Expenditure Models. Applied Economics, 33(9), 1131-1137.

[38]. Schofield, J.A. (1978); "Determinants of Urban Services Expenditures; fire and social services" in Local government studies, vol. 4 No 2, 65-80.

[39]. Ssewanyana, S and Younger, S. D. (2004), "Infant Mortality in Ugandu: Determinants, Trends and the Millennium Development Goals" African Development and Poverty Reduction: The Macro-Linkage, Forum Paper, October.

[40]. St. Leger, S. (2001), "The Anomaly that Finally Went. Away,” Journal of Epidemiology and Community Health, 55, 79.

[41]. Strauss, V. and Thomas, S. K. (1998), Human Capital Development Appraisal. IMF Working Paper, Vol 2 No. 6.

[42]. Temple, J.R. W (1999), “The New Growth Evidence," Journal of Economic Literature, March, 37(1), 112-156.22

[43]. UNICEF (1995), A State of the World's Children. Oxford University Press, Oxford.

[44]. Van Der Gaag, J. and Stimac, V. (2008), Towards a New Paradigm for Health Sector Development. Amsterdam: Amsterdam Institute for International Development.

[45]. Weil, T. P., (1995), Comparisons of medical technology in Canadian, German, and US Hospitals. Hospital \& Health Services Administration, 40 (4), 524.

[46]. WHO, The World Health Report (2004), Changing History. Geneva.

[47]. World Bank. (1993), World Development Report 1993: Investing in Health. Oxford University Press: New York, NY.

[48]. World Bank Tables (2010), World Development Indicator.

[49]. World Health Organisation (WHO): (1984) "Basic Document" Geneva.

[50]. Young, F. W. (2001), An Explanation of the Persistent Doctor-Mortality Association. Journal of Epidemiology and Community Health, 55, 80-84.

[51]. Zakir, M and Wunnava, P. V. (1999), "Factors Affecting Infant Mortality Rates:" Evidence from Cross-sectional Data" Applied Economics Letters, 6, 271-273 